\title{
HPV Related Retroperitoneal Squamous Cell Cancer: A Rare Presentation
}

\author{
Anita Agrawal ${ }^{1 *}$, Rajni Chibbar ${ }^{2}$, Anahita Safavi-Naini ${ }^{3}$ \\ ${ }^{1}$ Division of Gynecologic Oncology, Saskatoon Cancer Centre, University of Saskatchewan, Saskatoon, Canada \\ ${ }^{2}$ Department of Pathology and Laboratory Medicine, Saskatoon Health Region, University of Saskatchewan, Saskatoon, Canada \\ ${ }^{3}$ Medical College, University of Western Ontario, London, Canada \\ Email:*a.agrawal@usask.ca
}

How to cite this paper: Agrawal, A., Chibbar, R. and Safavi-Naini, A. (2016) HPV Related Retroperitoneal Squamous Cell Cancer: A Rare Presentation. Journal of Cancer Therapy, 7, 901-907. http://dx.doi.org/10.4236/jct.2016.712087

Received: August 24, 2016

Accepted: November 6, 2016

Published: November 9, 2016

Copyright $\odot 2016$ by authors and Scientific Research Publishing Inc. This work is licensed under the Creative Commons Attribution International License (CC BY 4.0).

http://creativecommons.org/licenses/by/4.0/

\section{Abstract}

Objective: To describe the primary carcinoma of the retroperitoneum that was positive for human papillomavirus (HPV), a surrogate molecular marker for high-risk HPV (p16) and p53. Methods: This is a case report. Results: We report a case of 50year-old woman with a large retroperitoneal mass (squamous cell carcinoma on histology) that was treated in September of 2014 with radical concurrent chemotherapy with weekly cisplatin and pelvic radiation (4500 cGY) and additional right pelvic boost of 900 cGY. It was assumed she had FIGO stage IIIB local advanced cervical cancer. She initially presented with the right leg swelling, severe pain and difficulty in walking and was treated with antibiotics for presumed cellulitis. Several months later right leg extensive deep vein thrombosis (DVT) was diagnosed and was started on anticoagulation. CT scan and MRI reported a large right-sided retroperitoneal mass occluding the illiac vessels and ureter. The mass had invaded into the adjacent pelvic sidewall, with destruction of the iliacus muscle and underlying iliac wing. MRI showed that the cervix and uterus were both normal. On examination cervix appeared grossly normal and cervical punch biopsy revealed HSIL only. CT-guided biopsy of the mass revealed a moderately differentiated squamous cell carcinoma positive for p16 and p53. Conclusion: Primary squamous cell carcinoma of the retroperitoneum is a real entity that is unknown. It is unclear if primary neoplasia in the cervix was small from which a cell clone arose and migrated to the retroperitoneal space.

\section{Keywords}

Primary Retroperitoneal Squamous Cell Carcinoma, HPV Infection, Cervical Neoplasia 


\section{Introduction}

In cases of advanced cervical cancer, usually woman presents with a vaginal bleeding an obvious cervical lesion in addition to other features such as hydronephrosis. Presence of a large retroperitoneal mass invading adjacent muscle and bone in the absence of cervical lesion and histologically confirmed squamous cell cancer is rare.

We report a case of 50-year-old woman with a large retroperitoneal mass (squamous cell carcinoma on histology) that was treated in September of 2014 with radical concurrent chemotherapy with weekly cisplatin and pelvic radiation (4500 cGY) and additional right pelvic boost of $900 \mathrm{cGY}$ for FIGO stage IIIB local advanced cervical cancer.

The patient initially presented with the right leg DVT and was treated with antibiotics for presumed cellulitis. Several months later right leg extensive deep vein thrombosis (DVT) was diagnosed and was started on anticoagulation. She was having significant pain in right leg and hip and difficulty in walking. Gynecologic oncology service was consulted in September 2014. On questioning she was also having irregular vaginal bleeding for about 4 - 6 months. The patient has history of last Pap smear 20 years ago.

On pelvic examination the cervix was firm and bulky but there was no external lesion. Uterus was found to be $8 \mathrm{~cm}$. An endometrial biopsy was obtained as well as a cervical punch biopsy was obtained on 9 September 2014.

Further work up with CT scan and MRI reported normal uterus and cervix (Figure 1) and a large right-sided retroperitoneal mass in close contact with rightilliac vessels and ureter (Figure 2 and Figure 3). The mass had invaded into the adjacent pelvic sidewall, with destruction of the iliacus muscle and underlying iliac wing. CT-guided biopsy of the mass was performed, and histology revealed a moderately differentiated squamous cell carcinoma positive for $\mathrm{p} 16$ and $\mathrm{p} 53$.

Patient was treated with radical concurrent chemo-radiation therapy and overall, she received $5400 \mathrm{cGy}$ including the boost in 30 fractions. The radiotherapy was well tolerated. Her pain had improved significantly.

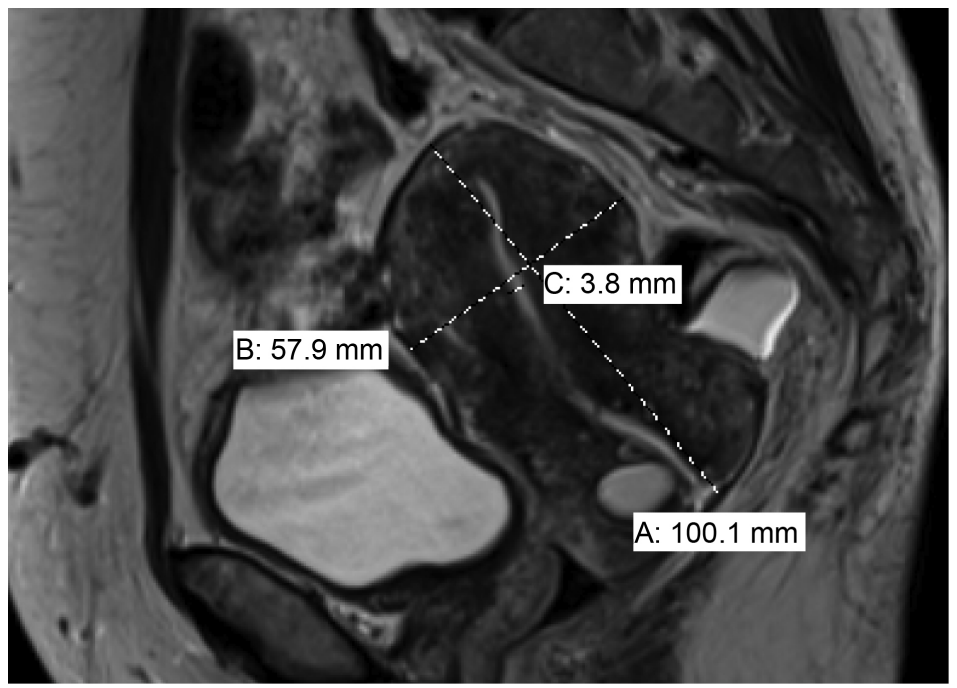

Figure 1. MRI reporting normal uterus and cervix. 


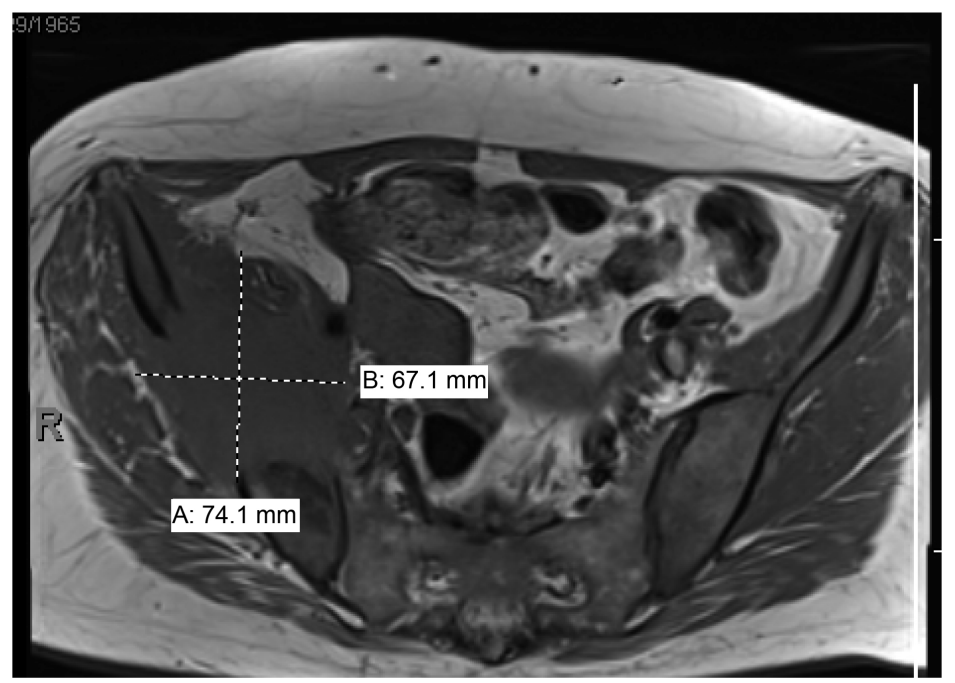

Figure 2. MRI reporting soft tissue mass invading iliacus muscle and right hip bone.

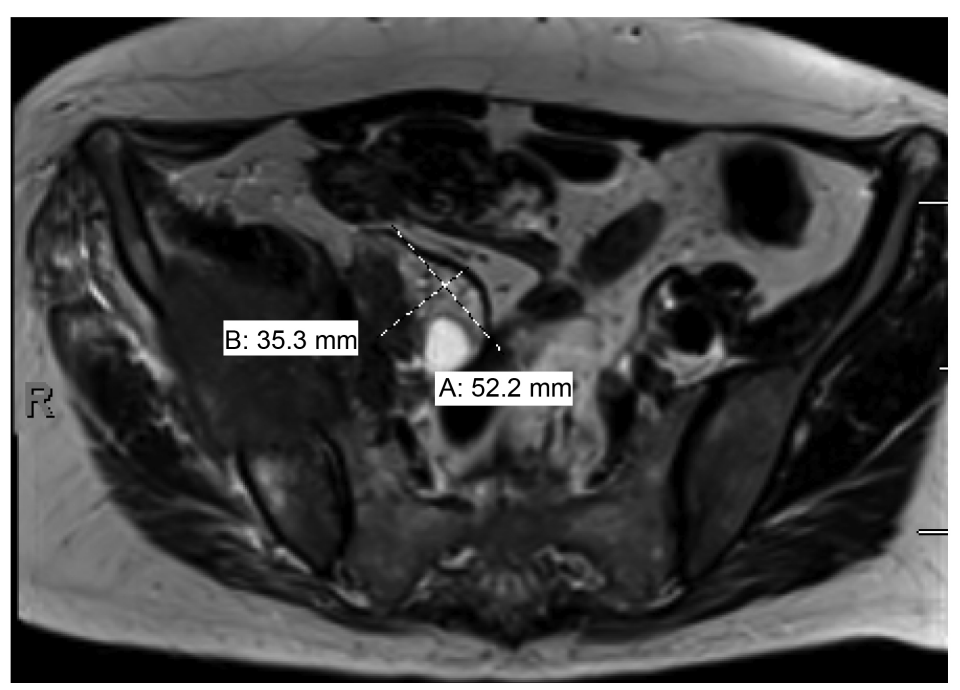

Figure 3. MRI reporting mass invading right hip bone including acetabulum.

After successful completion of treatment 2 months later follow up imaging reported decrease in size of retroperitoneal mass and no new disease and she is currently ambulating with help of a cane (Figure 4).

On 9 months follow up in 15 July 2015, she was found to have FDG avid retroperitoneal lymph nodes, three retroperitoneal lymph nodes which are quite FDG avid as well as the right iliac bone mass is FDG avid, but there is no FDG activity to the cervix and lungs are not well seen on PET scan and there is no FDG avid pulmonary nodules identified. She was offered second line chemotherapy with Cisplatin/Topotecan, Cisplatin day 1 , Topotecan day $1-3$ and was put on zometa monthly for persistent right iliacus mass invading bone. In December, she requested to take a break after four cycles because of chemo related fatigue and tinnitus and mouth sores and repeated upper 


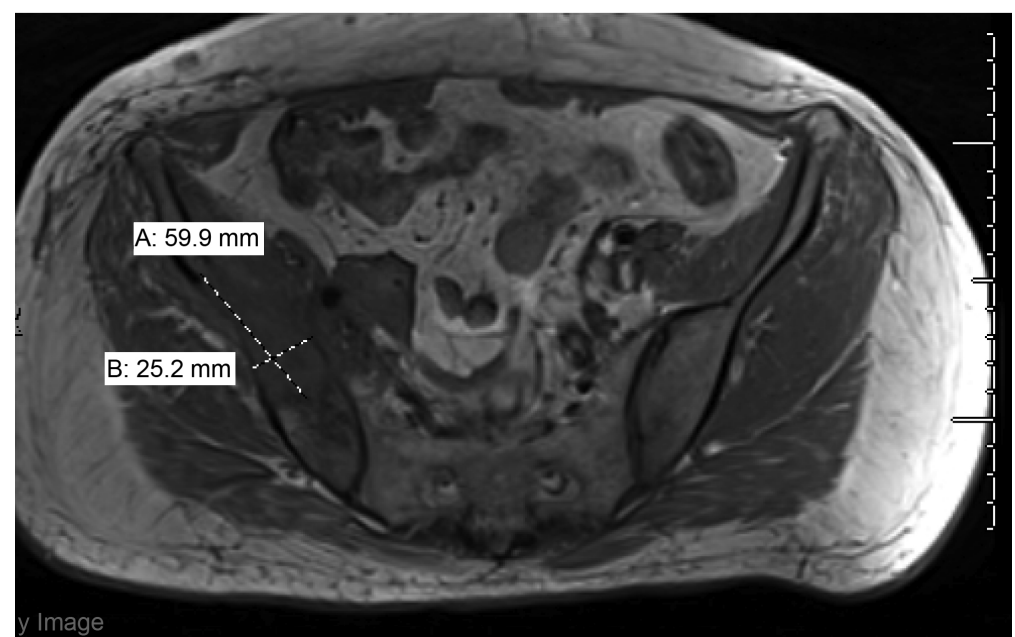

Figure 4. MRI 2 months post radiation and chemotherapy (smaller tumor).

respiratory tract infection.

CT scan follow up was done in Jan 2016 and it showed stable right iliac and nodal disease and on discussion patient had asked for 6 months follow up with PET before considering any further treatment. She was seen in August to discuss follow up PET done 27 July 2016. It reported slight increase in FDG activity in the retroperitoneal lymph nodes with few new lymphnodes in chest indicating disease progression. Patient chose to take no further systemic treatment. She also has stopped anticoagulation and currently on a herbal medicine which serves the similar purpose in her belief. Her ECOG status is 2 . She feels well and ambulating well and is currently asymptomatic except mild right leg swelling.

\section{Discussion}

\subsection{HPV Infection to Neoplasia}

HPV is spread by direct contact. Via micro-abrasions, the virus enters basal epithelial cells, which function as a reservoir. Low grade, subclinical infections primarily produce new viral particles. The viral life cycle progresses in concert with the rise of the basal cells to the surface, ending with apoptosis and desquamation, which releases the viral particles. Such infections have low malignant potential, since the HPV genome is in the form of a circular episome separate from the cell's genome, and therefore oncogene expression is low. High grade, neoplastic infections occur when the HPV DNA integrates into the host cell's genome at random sites, driving uncontrolled expression of the E6 and E7 oncogenes. These gene products cause unregulated cell proliferation by interfering with the function of tumor suppressor proteins such as $\mathrm{p} 53$, giving rise to monoclonal intraepithelial lesions (CIN 3) and invasive cancer. The E7 oncogene causes diffuse expression of p16INK4a in the basal epithelium, and this is why p16 is considered a specific marker for persistent high-risk HPV infection [1].

So, assuming that the p16 expressing retroperitoneal mass is indeed an HPV-related cancer, how did it arise? The simplest explanation is that there was indeed a microinva- 
sive component to the cervical neoplasia that is not visible on imaging, but sufficient for lymphatic invasion. In this scenario, the pelvic wall mass could have arisen from one or multiple iliac lymph nodes that subsequently coalesced into a single bulky mass.

\subsection{Multicentric HPV Lesions and the "HPV Field Effect"}

The alternate explanation is that the mass and the cervical neoplasia are synchronous HPV-related lesions. Such multicentric lesions are common in the lower genital tract. For example, $85 \%$ of women with vulvar dysplasia have synchronous cervical dysplasia [1].

Two competing models exist to explain the origin of multicentric HPV-related dysplastic lesions. The first, known as the HPV field effect, hypothesizes that a single HPV strain independently infects cells in different anatomic locations, leading to clonally distinct but (usually) synchronous lesions. The second model postulates a single transforming event in the cervix (whereby the HPV virus integrates into the genome and gives rise to a single clone of dysplastic cells), followed by migration of the infected cells themselves, resulting in clonally related, but metachronous lesions [1]. Vinokurova et al. found evidence for the latter model for lower genital tract lesions by looking at viral integration sites [2]. The HPV virus integrates into the cell's genome at random sites. Therefore, clonally related cells will have the same integration sites. In four out of five patients examined, the viral integration sites were the same for the initial pre-invasive cervical lesion and the subsequent vaginal or vulvar lesions, suggesting a common clonal origin in the cervix. Similarly, Kushima et al. demonstrated the same clonal migration from a cervical preinvasive lesion to upper genital tract lesions, and subsequent accumulation of genomic instability and invasive capacity.

\subsection{Migration to Peritoneum}

The precise process of migration is unknown, but seems to be a form of discontinuous epithelial spread of transformed basal epithelial cells. Minimally invasive endocervical adenocarcinomas have been shown to metastasize directly to the ovary, with no disease in the uterus, lymph nodes, or other tissues [3]. The primary cervical lesions and the secondary ovarian endometrioid/mucinous tumors are positive for the same HPV type.

In one study, ovarian metastases from endocervical carcinomas were associated with lower uterine segment invasion, but not lymph node positivity [4]. This suggests migration of dysplastic cells via retrograde spread into the upper genital tract, and potentially, into the peritoneal space. Such retrograde dissemination is well known for endometriosis, ectopic pregnancy, fibroid tissue, and peritoneal implants from fallopian tube neoplasia. Further migration to the retro-peritoneal space could be either via direct invasion through the peritoneal membrane; or transmission of cell clones through lymphatic vessels. The latter mechanism has been implicated in retroperitoneal ectopic pregnancies [5].

\subsection{Primary Squamous Cell Carcinomas of the Retroperitoneum}

The final option is that this could be an intraepithelial lesion of the cervix with an inci- 
dental primary squamous cell carcinoma of the retroperitoneum. However, such cancers are exceedingly rare in the medical literature. There is one nearly unequivocal case presenting as a complex cystic mass obstructing the ureter. There was no evidence of disease anywhere in the hysterectomy specimen, however, pathology suggested an origin in the peri-ureteral tissue [6]. There is also a series of six cases of primary retroperitoneal squamous cell carcinoma with negative pap smear and pelvic examination at diagnosis (two patients had a remote history of a positive pap test) [7]. All six cases were positive for p16, and four were positive for HPV as well. Finally, there is a case of metastatic squamous cell carcinoma of the iliac lymph nodes with unknown primary and negative pap test [8]. Most of the above cases have been poorly differentiated carcinomas with squamous features.

Whether primary squamous cell carcinoma of the retroperitoneum is a real entity is unknown. It is possible that the primary neoplasia in each of these cases was a very small, undetected pre-invasive or minimally cervical lesion, from which a cell clone arose and migrated to the retroperitoneal space, as described above. It is also possible that the cervical lesions subsequently resolved, as many cases of CIN are known to do.

\subsection{Migration to Retroperitoneum}

If migration to the peritoneal cavity is by retrograde flow of neoplastic cells, a final destination in the retroperitoneum is more difficult to explain. Rarely, both endometriosis and human embryos have been discovered in the retroperitoneal space. Most retroperitoneal ectopic pregnancies are found high along the aorta [9]. Given that the fundus of the uterus drains to the para-aortic lymph nodes, this has been proposed as the most likely route taken by the wayward embryos [5]. Furthermore, retroperitoneal ectopic pregnancies have been found in close proximity to lymphoid tissue [5] [9]. Certainly, this explanation can be adapted to fit our case. We can imagine retrograde flow of neoplastic cell clones from a cervical intraepithelial neoplasia to the body of the uterus, which subsequently drains via lymphatic channels along the internal iliac vessels to the common iliac bifurcation. If the bifurcation was the initial site of tumor growth, this could account for the early presentation of right leg pain and swelling in our patient.

\section{Conclusion}

Above, we have attempted to reconcile the rare case of a woman presenting with a locally advanced cervical cancer in the absence of a cervical mass. Through review of the literature, we have found mechanisms whereby a cervical intraepithelial neoplasia could give rise to a lateral retroperitoneal mass.

\section{References}

[1] Hampl, M., Wentzensen, N., Vinokurova, S., von Knebel-Doeberitz, M., Poremba, C., Bender, H.G., et al. (2007) Comprehensive Analysis of 130 Multicentric Intraepithelial Female Lower Genital Tract Lesions by HPV Typing and p16 Expression Profile. Journal of Cancer Research and Clinical Oncology, 133, 235-245.

http://dx.doi.org/10.1007/s00432-006-0162-0 
[2] Vinokurova, S., Wentzensen, N., Einenkel, J., Klaes, R., Ziegert, C., Melsheimer, P., et al. (2005) Clonal History of Papillomavirus-Induced Dysplasia in the Female Lower Genital Tract. Journal of the National Cancer Institute, 97, 1816-1821. http://dx.doi.org/10.1093/jnci/dji428

[3] Ronnett, B.M., Yemelyanova, A.V., Vang, R., Gilks, C.B., Miller, D., Gravitt, P.E., et al. (2008) Endocervical Adenocarcinomas with Ovarian Metastases: Analysis of 29 Cases with Emphasis on Minimally Invasive Cervical Tumors and the Ability of the Metastases to Simulate Primary Ovarian Neoplasms. The American Journal of Surgical Pathology, 32, 1835-1853. http://dx.doi.org/10.1097/PAS.0b013e3181758831

[4] Tabata, M., Ichinoe, K., Sakuragi, N., Shiina, Y., Yamaguchi, T. and Mabuchi, Y. (1987) Incidence of Ovarian Metastasis in Patients with Cancer of the Uterine Cervix. Gynecologic Oncology, 28, 255-261. http://dx.doi.org/10.1016/0090-8258(87)90170-3

[5] Liang, C., Li, X., Zhao, B., Du, Y. and Xu, S. (2014) Demonstration of the Route of Embryo Migration in Retroperitoneal Ectopic Pregnancy Using Contrast-Enhanced Computed Tomography. The Journal of Obstetrics and Gynaecology Research, 40, 849-852. http://dx.doi.org/10.1111/jog.12233

[6] Khalil, A.M., Shabb, N.S., Hourani, M.H., Shamseddine, A.I., El-Hajj, M.I. and Seoud, A.F. (2005) Primary Squamous Cell Carcinoma of the Pelvic Retroperitoneum Presenting as an Adnexal Mass: A Case Report. Journal of Obstetrics and Gynaecology: The Journal of the Institute of Obstetrics and Gynaecology, 25, 92-93. http://dx.doi.org/10.1080/01443610400025523

[7] Clements, A., Euscher, E., Lacour, R., Merritt, W., Klopp, A. and Ramondetta, L. (2010) The Presence of Human Papillomavirus or p16 in Six Cases of Retroperitoneal Carcinoma. Obstetrics and Gynecology, 116, 1042-1046. http://dx.doi.org/10.1097/AOG.0b013e3181f88ddf

[8] Matsuyama, S., Nakafusa, Y., Tanaka, M., Yoda, Y., Mori, D. and Miyazaki, K. 2006 () Iliac Lymph Node Metastasis of an Unknown Primary Tumor: Report of a Case. Surgery Today, 36, 655-658. http://dx.doi.org/10.1007/s00595-006-3211-Z

[9] Persson, J., Reynisson, P., Masback, A., Epstein, E. and Saldeen, P. (2010) Histopathology Indicates Lymphatic Spread of a Pelvic Retroperitoneal Ectopic Pregnancy Removed by Robot-Assisted Laparoscopy with Temporary Occlusion of the Blood Supply. Acta Obstetricia et Gynecologica Scandinavica, 89, 835-839.

http://dx.doi.org/10.3109/00016341003623779 
Submit or recommend next manuscript to SCIRP and we will provide best service for you:

Accepting pre-submission inquiries through Email, Facebook, LinkedIn, Twitter, etc. A wide selection of journals (inclusive of 9 subjects, more than 200 journals)

Providing 24-hour high-quality service

User-friendly online submission system

Fair and swift peer-review system

Efficient typesetting and proofreading procedure

Display of the result of downloads and visits, as well as the number of cited articles

Maximum dissemination of your research work

Submit your manuscript at: http://papersubmission.scirp.org/

Or contact jct@scirp.org 